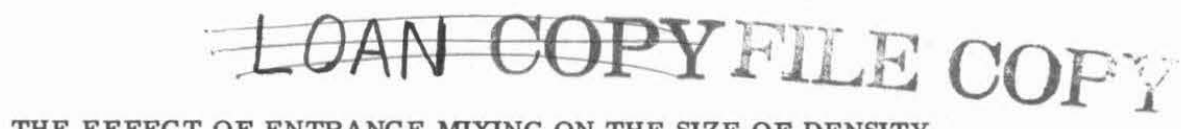

\title{
THE EFFECT OF ENTRANCE MIXING ON THE SIZE OF DENSITY CURRENTS IN SHAVER LAKE
}

\section{Hugh Stevens Bell}

\begin{abstract}
The present paper discusses entrance mixing and presents data that were obtained during June 1944, at Shaver Lake, California. We believe that no previous attempt has been made to study entrance mixing under field conditions.
\end{abstract}

Introduction--A density current is a gravity flow of a liquid or a gas through, under, or over a fluid of approximately equal density. Such currents may be differentiated, respectively, as interflows, underflow, and overflow. In 1943 Robert T. Knapp outlined and discussed briefly the mixing characteristics, of density currents in lakes and reservoirs [see "Reference" at end of paper, KNAPP, 1943]. After establishing two main categories, (1) localized mixing, and (2) general mixing, he subdivided the former into (a) entrance mixing, (b) plunge-point mixing, and (c) mixing due to channel irregularities. Physically, there is ample justification for these three subdivisions. Recent field experience, however, indicates that it is more convenient to treat plunge-point mixing as if it were merely the final stages of entrance mixing. Consequently, the term, "entrance mixing" as used herein includes plunge-point mixing。

Purpose of the investigation--When a stream enters a body of still water, mixing takes place between the inflowing and the impounded water. KNAPP [1943, pp. 294-295] points out that there is intense local mixing at the point of entrance, where large amounts of energy are made available through the shock losses involved in the change of momentum. The field studies at Shaver Lake were undertaken in order to learn at least the order of magnitude of entrance mixing.

Density currents normally follow the union of any stream with a body of still water. The specific gravity of the one is rarely, if ever, the same as that of the other, and although there are exceptions, any mixing of the two may be expected to produce a third mass of intermediate specific gravity. Under favorable conditions a current is possible when the specific gravity of the mixture varies as little as 0.01 per cent from that of the impounded water. This is approximately the difference between water at $69^{\circ}$ and $70^{\circ} \mathrm{F}$.

Shaver Lake--Shaver Lake is located about 40 miles northeast of Fresno, California. It lies at an elevation of 5370 feet, midway between Yosemite and Sequoia National Parks in the Sierra Nevada Mountains. The capacity is about 135,000 acre feet. It is the largest of the three main storage reservoirs of the Big Creek-San Joaquin River hydro-electric development of the Southern California Edison Company. Runoff from the immediate watershed is of little importance. The principal inflow occurs during May, June, and July, when approximately 115,000 acre feet are diverted from Huntington Lake and Pitman Creek. This water flows through a tunnel to a point some three miles from Shaver Lake and 1300 feet higher. There it enters the North Fork of Stevenson Creek, known locally as Tunnel Creek, and continues down a steep, rocky, natural channel until it reaches the Lake.

Shaver Lake was chosen as the site for the field studies because this inflow, which is measured and controlled to a considerable degree, is invariably colder than the surface stratum of the Lake. This practically guarantees subsurface density currents. Furthermore, conditions remain sur-

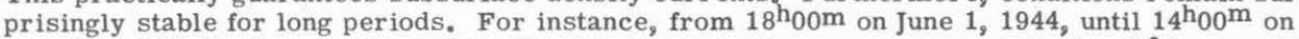
June 14, 1944, the temperature of the Tunnel Creek discharge was never less than $90^{\circ} 8$ or more than $13: 5 \mathrm{~F}$ colder than the surface stratum in the reservoir. The mean temperature difference was $11: 8 \mathrm{~F}$, and the mean difference in specific gravity was not quite 0.001 . During that same period the discharge varied from $1100 \mathrm{cfs}$ to $1250 \mathrm{cfs}$. The maximum fluctuation in 24 hours was only $90 \mathrm{cfs}$. The entrance velocity was roughly $12 \mathrm{fps}$. The water was so remarkably free from suspended sediment and dissolved minerals that specific-gravity determinations of sufficient accuracy could be made solely upon the basis of temperature.

Tunnel Creek and a small, apparently nameless stream, enter the reservoir in a bay which, at spillway level, has a surface area of about 20 acres and a capacity of some 500 or 600 acre feet. 
Although the small stream discharges as much as $20 \mathrm{cfs}$ late in May, this dwindles to less than five cfs by the end of June. Because this flow was always less than two per cent, usually nearer one per cent, of that from Tunnel Creek, it has been neglected in making calculations.

The zone of entrance mixing lies within the small bay. The most useful data were obtained on a cross section (C C) established some 1600 feet from the mouth of Tunnel Creek, just outside the moderately restricted entrance to the bay. The locations of this and the three other cross sections shown in Figure 1 were determined before going into the field by constructing a 1:400 model of the upper portion of the reservoir basin. Dyes made it easy to observe the paths taken by laboratory density currents. In the field they had to be hunted with current meters and thermometers, but their favorite routes were known from the model studies.

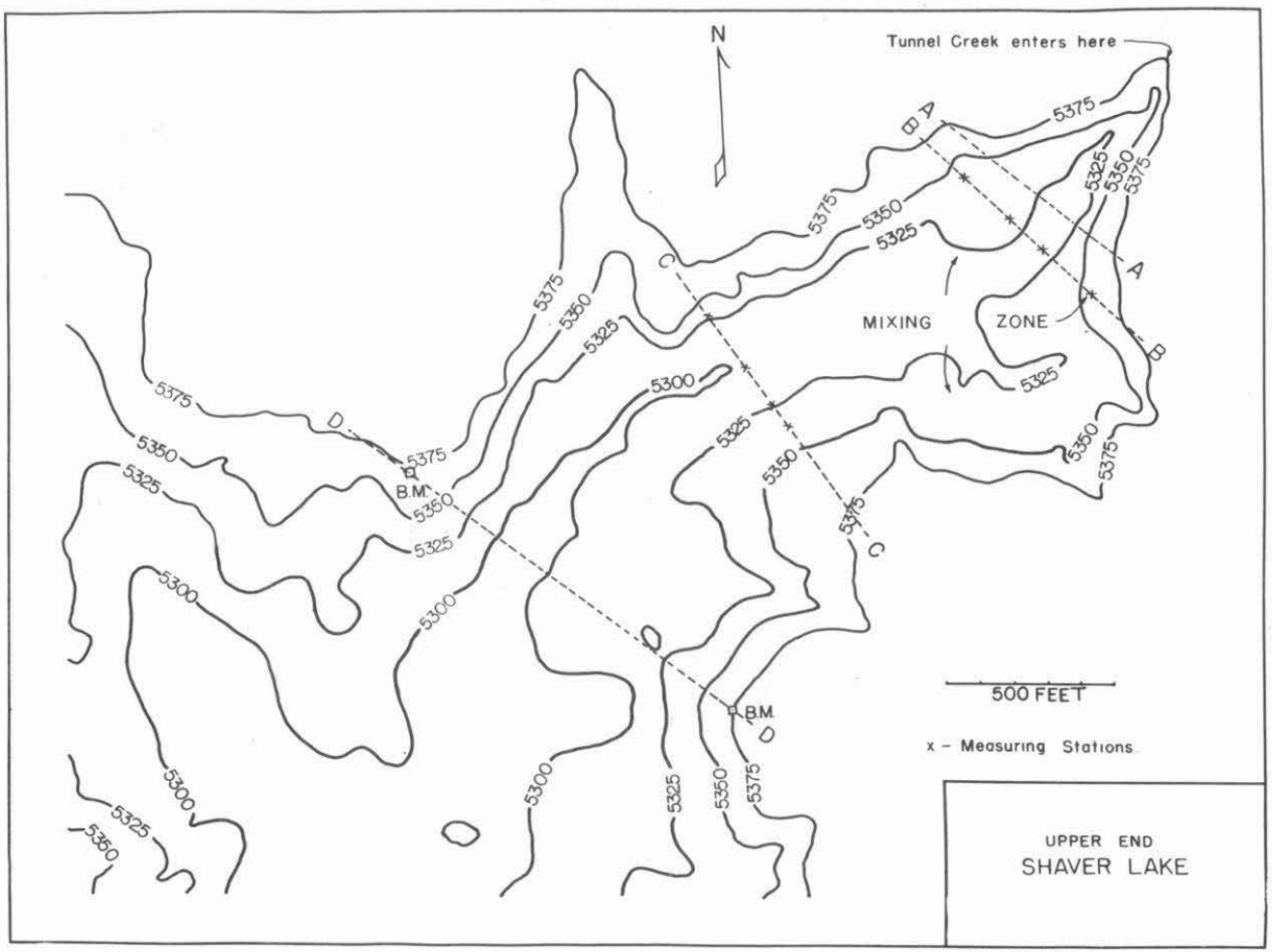

Fig. 1--Contour map of the upper end of Shaver Lake showing the four cross sections at which observations were made and the location of measuring stations mentioned in the text

A boat could be positioned nicely on any cross section with the aid of pairs of markers that were set on opposite shores. Exact positions were located with an alidade on a base map supplied by the Southern California Edison Company, whose fine cooperation before, during, and after the field investigation did much to assure success. The water was from 50 to 70 feet deep at midchannel and three or even four anchors were needed occasionally to keep the boat on station.

Methods of approach--The physical conditions at Shaver Lake offer two rather obvious opportunities for evaluating entrance mixing. (1) Reservoir water that is mixed with that of Tunnel Creek flows downstream as part of a density current and must be replaced. In the Lake this gives rise to upstream currents whose combined flow represents approximately the mixing demand, that is, the quantity of stored water per unit time consumed by entrance mixing. Therefore, if the flow of these upstream currents can be determined, the problem is solved. (2) If the flow of the downstream density current czn be ascertained, the mixing demand can then be established by subtract ing from it the known inflow from Tunnel Creek。 
Assuming that sufficiently accurate data are obtainable, either method offers a very straight. forward solution of the problem. They require merely the determination of the flow of one or more currents within the reservoir and the readily available discharge data for Tunnel Creek, Good data on the reservoir currents were difficult to obtain because velocities in the Lake never exceeded $0.8 \mathrm{fps}$, and at most of the stations rarely reached $0.5 \mathrm{fps}$. The current meter, therefore, had to be used almost always in its least dependable range. Under such circumstances bobbing and drifting may become sources of serious error. To mininize this a heavy boat was used with several anchors.

Before the field work was begun, a third approach, based largely upon temperature measurements, seemed to offer a method requiring a minimum of data and a single simple calculation. It was reasoned that since the discharge of Tunnel Creek could be learned from stage-recorder data, and its temperature readily measured, it would be easy to calculate how much water from the surface layer must be mixed with that of Tunnel Creek to provide a fluid mass having the temperature of the density current flowing from the mixing area. This approach was particularly attractive because temperatures can be measured more easily and much more accurately than can velocities under field conditions. This is especially true when velocities are low, as they usually are in density currents.

Three assumptions were made: (1) The impounded water used in entrance mixing would be supplied by a single layer in which (2) temperature gradients would be lacking or negligible and (3) the current flowing out of the mixing area would be of uniform temperature.

Unfortunately, all three of these basic assumptions were false. There were always two, occasionally three, upstream currents supplying reservoir water to the mixing zone. Vertical and horizontal temperature and velocity gradients were present in all of them. Under such circumstances temperature measurements, no matter how numerous or accurate they may be, are of little value in themselves. They permit us to determine the mean temperature of the water in a cross-section at a particular time, but the third method requires us to know the mean temperature of the flow through the cross-section. If there are velocity gradients but no temperature gradients, or vice versa, the two values are identical, but when both gradients are present the values may differ widely because one is derived from temperatures and areas only while the other takes velocities into consideration also. This means that the third method as originally conceived could not be used, since it gave no consideration whatever to velocities.

A modified form of the third method, based upon heat flow rather than upon mean temperature, can be used because the necessary data on areas, temperatures, and velocities are at hand. Although it makes use of highly dependable temperature measurements, it also uses the less accurate velocity data. Consequently, it fails to give a simple and independent solution of the mixing problem.

Expressed mathematically, Methods 1 and 2 are

$$
\begin{aligned}
& \mathrm{Q}_{\mathrm{m}}=\mathrm{Q}_{-} \ldots \ldots \ldots \ldots \ldots \ldots \ldots \ldots \ldots \\
& Q_{m}=Q_{+}-Q_{c} \ldots \ldots \ldots \ldots \ldots
\end{aligned}
$$

where $Q_{m}$ is the rate at which impounded water is mixed with the inflow, $Q_{+}$is the total rate of flow downstream in the Lake, $Q_{-}$is the upstream flow in the Lake, and $Q_{c}$ is the flow into the Lake. At Shaver Lake, $Q_{-}$was composed of a surface flow, $Q_{S}$, and an underflow, $Q_{u}$. In the calculations Q. has been replaced by the sum of these two flows. The downstream flow was an interflow and, for clarity, is represented by $Q_{1}$ rather than $Q_{+}$as above.

The expressions for Method 3 may be derived by equating the heat flow into the mixing zone to that out of the zone,

$$
\sum w \gamma \Delta Q_{-} T_{-} \Sigma w \gamma \Delta Q_{e} T_{e}=\Sigma w \gamma \Delta Q_{+} T_{+}
$$

where the $Q$ terms are elements of flow in the respective streams, $T$ represents the temperature of the elements, $w$ is the specific weight of water, $\gamma$ is the specific heat value for water, and $\Sigma$ denotes summation over the cross-section of each stream. Each term can be evaluated numerically from the measured data. The numerical result will be the quantity of heat flow per unit time. The first term will become

$$
\sum w \gamma \Delta Q_{-} T_{-}=w \gamma Q_{-} \bar{T}
$$


where, by definition, $\overline{\mathbf{T}}_{-}$is the average temperature in the upstream flow, $\mathbf{Q}_{-}$, in the Lake. The heat-flow equation now becomes

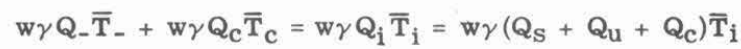

and the mixing rate is

$$
Q_{m}=Q_{-}=Q_{S}+Q_{u}=\left(Q_{s} \bar{T}_{s}+Q_{u} \bar{T}_{u}+Q_{c} \bar{T}_{c}\right) / \bar{T}_{i}-Q_{c}
$$

Equipment--Temperature measurements in Tunnel Creek and at the Lake surface were made with a solid-stem thermometer graduated in tenths of a degree Centigrade; temperatures below the surface were obtained by using a bathythermograph (an instrument that records temperatures against depth) and a reversing thermometer which could be read with ease to the nearest tenthdegree Centigrade. Velocities were determined with a Price current meter which had been rated to $0.05 \mathrm{fps}$ by the National Bureau of Standards. Depths were measured to the nearest tenth of a foot for all instruments by means of revolution counters on the hoisting reels. Wind velocities were estimated.

The direction in which currents flowed was determined by observing, with the aid of a glassbottomed box, either the current-meter weight or the highly polished fins on the current meter. The fins were visible to depths of about 45 feet. Directions for currents at greater depths were assumed after studying temperature and velocity data. This was not too difficult, because at the only station were the problem was encountered, the topography was such that in the greater part of the area where direct observation was not possible the flow virtually had to be normal to the crosssection, as indicated by Figures 1 and 3. It was necessary, therefore, only to decide whether it was upstream or downstream.

Presentation of data--On June 6 and 7, 1944, measurements were made of temperatures and welocities at four stations on cross section CC. This location was immediately downstream from the point at which inf ows of $100 \mathrm{C}$ to $1250 \mathrm{cfs}$ appeared to plunge beneath the surface.

Data for these two days are combined because they supplement each other even though those for neither day are adequate for the flow through the cross-section to be calculated. This treatment seems permissible because of the similarity of conditions on the two days. Inflow from Tunnel Creek fluctuated between 1115 and $1160 \mathrm{cfs}$, and the mean was $1138 \mathrm{cfs}$. At Shaver Dam the maximum and minimum air temperatures were $71^{\circ}$ and $47^{\circ} \mathrm{F}$ on June $6,72^{\circ}$ and $48^{\circ}$ on June 7 .

Measurements made at a vertical located at the center, that is, at the point where the water was deepest, show that there were three distinct currents flowing through the cross-section: (1) A surface current from four to six feet deep, upstream and normal to the cross-section; (2) an interflow about 37 feet deep, downstream and passing through the section at an angle of approximately $65^{\circ} ;(3)$ an underflow about 24 feet deep, upstream and normal to the cross-section. Figure 2 is a schematic presentation of the circulation pattern within the mixing zone and shows velocity and temperature profiles for the several currents at the center of cross-section CC, The upper two currents were detected also at stations located on the same cross-section 185 feet

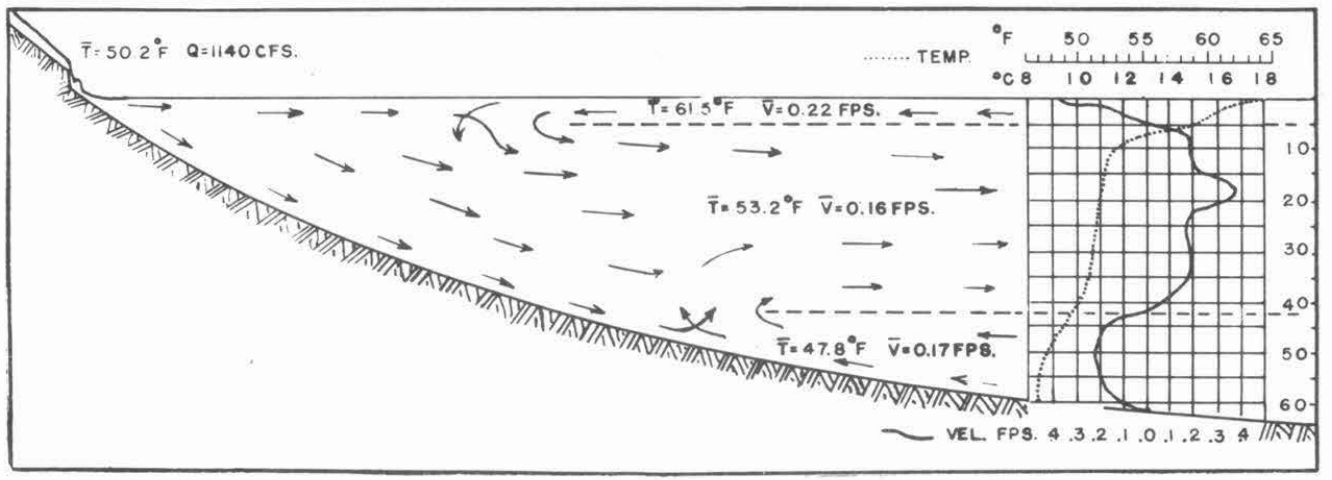

Fig. 2--Schematic presentation of flow in mixing zone with accompanying velocity and temperature profiles at center of cross-section CC, Shaver Lake, June 6 and 7, 1944 
to the north and $\mathbf{1 5 5}$ feet to the south of the center. Only the surface current could be identified at a station 235 feet south of the center. At the most northerly station it was not over two feet thick as compared with more than seven feet at the southermost station. The difference in thickness is probably due to the fact that the interflow tends to "pile up" on the north shore, by which it is forced to alter its course. The wedgelike cross section of the surface layer is shown in Figure 3, the primary purpose of which is to show the locations of the four stations on cross section CC, the temperature and velocity distributions at each, and the velocity contours of the interflow.

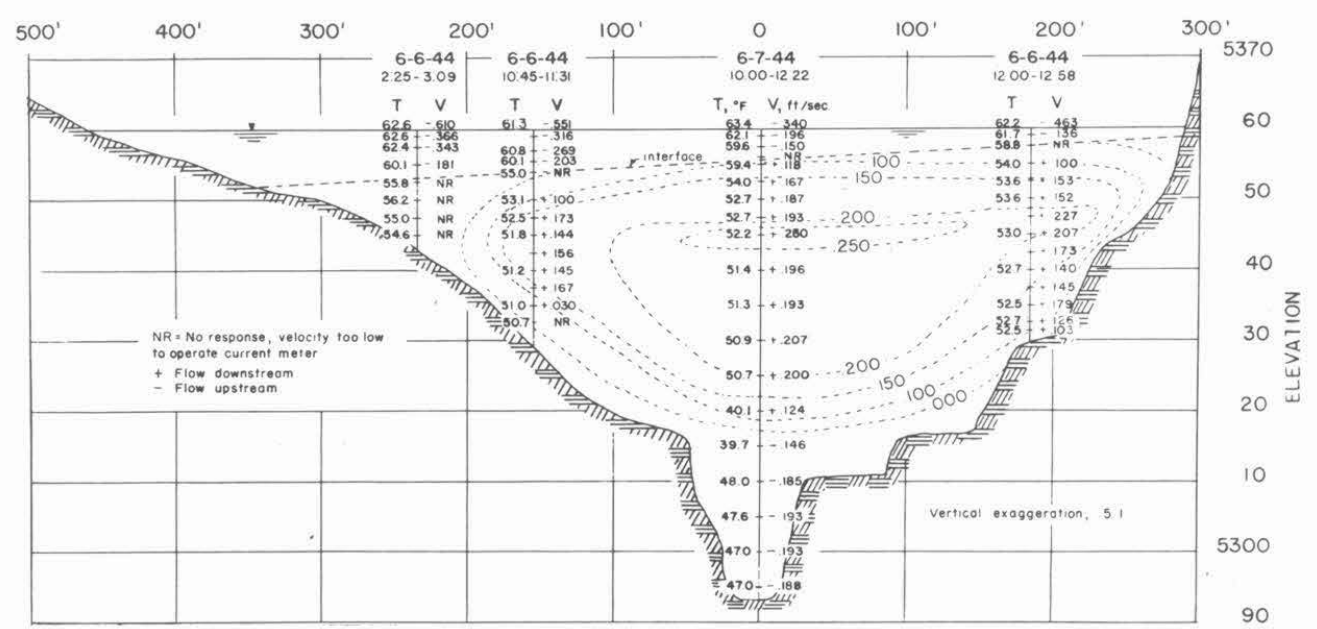

Fig. 3--Diagram of cross-section CC showing velocities and temperatures on four verticals, and indicating velocity contours for interflow, Shaver Lake, June 6 and 7, 1944

Table 1 gives all data needed to calculate the magnitude of entrance mixing by the methods outlined. The equations for calculating $Q_{m}$, the rate at which mixing occurs, and $\bar{T}_{i}$, the mean temperature of the interflow, are given with numerical results in Table 2。 Apparently the impounded water used in entrance mixing was equal to from 75 per cent to 96 per cent of the discharge of Tunnel Creek. In other words, the interflow had a volume roughly twice as great as that of Tunnel Creek.

Table 1-- Summary of data, section CC, June 6 and 7,1944

\begin{tabular}{|c|c|c|c|c|c|c|c|c|}
\hline \multicolumn{2}{|c|}{ CURRENT } & \multicolumn{2}{|c|}{ DISCHARGE } & \multirow{2}{*}{\begin{tabular}{|l|} 
AREA \\
sq.ft.
\end{tabular}} & \multirow{2}{*}{\begin{tabular}{|c|} 
MEAN \\
VELOCITY \\
V(fps) \\
\end{tabular}} & \multicolumn{2}{|c|}{$\begin{array}{c}\text { MEAN } \\
\text { TEMPERATURE }\end{array}$} & \multirow[t]{2}{*}{$\begin{array}{l}\text { SPECIFIC } \\
\text { GRAVITY }\end{array}$} \\
\hline DESCRIPTION & DIRECTION & $Q(c f s)$ & SYMBOL & & & $\overline{\mathrm{T}}^{\mathrm{a}}\left({ }^{\circ} \mathrm{F}\right)$ & SYMBOL & \\
\hline SURFACE & UPSTREAM & 744 & $Q_{S}$ & 3460 & 0.215 & 61.5 & $\overline{\mathrm{T}}_{\mathrm{s}}$ & 0.998882 \\
\hline INTERFLOW & DOWNSTREAM & 1989 & $Q_{i}$ & 13900 & 0.159 & 53.2 & $\overline{\mathrm{T}}_{\mathrm{i}}$ & 0.999523 \\
\hline UNDERFLOW & UPSTREAM & 340 & $Q_{u}$ & I 997 & 0.170 & 47.8 & $\overline{\mathrm{T}}_{\mathrm{u}}$ & 0.999796 \\
\hline TUNNEL CREEK & DOWNSTREAM & 1138 & $Q_{c}$ & & & 50.2 & $\overline{\mathrm{T}}_{\mathrm{c}}$ & 0.999691 \\
\hline
\end{tabular}

Several points deserve brief discussion. The combined flow of the upstream density currents and Tunnel Creek was $2222 \mathrm{cfs}$, which should equal the interflow. The cross sectional area of the latter, when multiplied by its mean velocity, indicates a flow of $2210 \mathrm{cfs}$. This nearly perfect agreement vanishes when account is taken of the angle at which the current passes through the cross section. With this correction $Q_{\mathrm{i}}$ becomes $1989 \mathrm{cfs}$. 
Table 2--Data on entrance mixing and interflow temperature, section CC, June 6, 7, 8, 1944

\begin{tabular}{|c|c|c|c|c|}
\hline \multicolumn{3}{|c|}{ ENTRANCE MIXING } & \multicolumn{2}{|l|}{ INTERFLOW MEAN TEMP. } \\
\hline \multirow[t]{2}{*}{ HOW OBTAINED } & $\begin{array}{l}\text { MIXING RATE } \\
Q_{m} \text { (cfs) }\end{array}$ & $\begin{array}{l}\text { MIXING RATIO } \\
Q_{m} / Q_{c}\end{array}$ & HOW OBTAINED & \multirow[t]{2}{*}{$\overline{T_{i}}\left({ }^{\circ} \mathrm{F}\right)$} \\
\hline & \multicolumn{3}{|c|}{ USING DATA FROM TABLE 1} & \\
\hline \multirow{3}{*}{$\begin{array}{l}E Q \text { (Ia) } Q_{s}+Q_{u}=Q_{m} \\
E Q \text { (2a) } Q_{i}-Q_{c}=Q_{m}\end{array}$} & 1084 & 0.96 & $E Q(3 a) \frac{Q_{s} T_{s}+Q_{u} T_{u}+Q_{c} T_{c}}{Q_{s}+Q_{u}+Q_{c}}=T_{i}$ & 53.6 \\
\hline & 851 & 0.75 & GRAPHICAL INTEGRATION & \multirow[t]{2}{*}{53.2} \\
\hline & \multicolumn{3}{|c|}{ USING ADJUSTED VALUES OF $Q_{S} \& Q_{u}$} & \\
\hline $\begin{array}{l}Q_{m} \text { ASSUMED } \\
\text { SEE TEXT }\end{array}$ & 851 & 0.75 & $E Q$ (3a) & 53.2 \\
\hline $\begin{array}{l}\text { EQ(Ia) AFTER SOLV- } \\
\text { ING EQ.(3a) FOR } Q_{S}\end{array}$ & 973 & 0.85 & ASSUMED & 53.2 \\
\hline
\end{tabular}

Equation (2a) of Table 2 makes use of very satisfactory discharge data for Tunnel Creek, and interflow data which are the most abundant and probably the most dependable obtained for any of the reservoir currents. According to it the mixing rate, $Q_{m}$, is 851 cfs. But $Q_{s}+Q_{u}=Q_{m}$, which, as Table 2 shows, is $1084 \mathrm{cfs}$. The latter value of $Q_{m}$ is more than 28 per cent greater than the former. Because of the better quality of the data used in Equation (2), the smaller value is more acceptable.

The top portion of the righthand section of Table 2 shows that a mean temperature of $53^{\circ} 6 \mathrm{~F}$ would be obtained by combining the discharges of the upstream reservoir currents with that of Tunnel Creek. A graphical integration of the interflow data indicates only $53: 2 \mathrm{~F}$. In view of the difference in the rate of mixing as calculated by equation (1a) and (2a) this close agreement is surprising. $T_{1}$ apparently is not a very sensitive index of entrance mixing.

Granted field data and methods of calculation that are flawless, the values of $Q_{m}$ should be nearly identical whether they are found by (1a) or (2a). So also should the values of $\mathrm{T}_{1}$ whether they are determined by graphical integration of heat-flow measurements of the interflow, or by (3a).

Equation (3a) is convenient for trying out various assumptions and see how they will affect - $Q_{m}$ and $\bar{T}_{1}$. Since temperature data are probably more accurate than discharge data, let it be assumed that the values of $\widehat{T}$ as shown in Table 1 are correct, that the tabulated values of $Q_{1}$ and $Q_{c}$ are also correct, but that $Q_{S}+Q_{u}$ is $851 \mathrm{cfs}$ as indicated by (2a). The ratio $Q_{S} / Q_{u}$, by Table 1 , is $744 / 340$. If $Q_{\mathrm{S}}$ is adjusted to $584 \mathrm{cfs}$ and $\mathrm{Q}_{\mathrm{u}}$ to $267 \mathrm{cfs}$ their total is $851 \mathrm{cfs}$ and their ratio is as $744 / 340$. When these new values are substituted in $(3 \mathrm{a}), \overline{\mathrm{T}}_{1}$ becomes $53^{\circ} 2$, which is identical with the value derived from a graphical integration of the completely independent data for the interflow.

Several factors conspire to make $Q_{\mathrm{S}}$ the least dependable value in Table 1. If it is assumed, then, that all other values in that Table are correct, and (3a) is solved for $Q_{S}$, the answer is $633 \mathrm{cfs}$ and $Q_{m}$ becomes $973 \mathrm{cfs}$. This indicates a mixing rate falling nearly midway between those determined by the other methods. The lower half of Table 2 shows the-influence of various adjustments on $Q_{m}$ and $\bar{T}_{i}$.

The differences in specific gravity were very small, as may be seen in the final column of Table 1. Between the water of Tunnel Creek and that of the surface current the difference was 0.0008 , but between Tunnel Creek and the underflow it was only 0.0001 . For the sake of comparison, one ounce of sediment suspended in a cubic foot of water increases the specific gravity 0.0006 , and the difference between the specific gravity of sea water and fresh water is about 0.025 . 
Iune 28, 1944--Figure 4 presents velocity and temperature profiles for June 28,1944 , at four stations on cross section CC, and Tables 3 and 4 provide a summary of the data. The discharge of Tunnel Creek was $625 \mathrm{cfs}$ as compared with about.1140 cfs on June 6 and 7, 1944 .

Table 3--Summary of data, section CC, June 28,1944

\begin{tabular}{|c|c|c|c|c|c|c|c|c|}
\hline \multicolumn{2}{|c|}{ CURRENT } & \multicolumn{2}{|c|}{ DISCHARGE } & \multirow{2}{*}{\begin{tabular}{|l} 
AREA \\
sq. ft
\end{tabular}} & \multirow{2}{*}{\begin{tabular}{|l}
$\begin{array}{c}\text { MEAN } \\
\text { VELOCITY }\end{array}$ \\
V(fps)
\end{tabular}} & \multicolumn{2}{|c|}{$\begin{array}{c}\text { MEAN } \\
\text { TEMPERATURE }\end{array}$} & \multirow[t]{2}{*}{$\begin{array}{l}\text { SPECIFIC } \\
\text { GRAVITY }\end{array}$} \\
\hline DESCRIPTION & DIRECTION & $Q(c f s)$ & SYMBOL & & & $\bar{T}^{a}\left({ }^{\circ} \mathrm{F}\right)$ & SYMBOL & \\
\hline SURFACE & UPSTREAM & 336 & $Q_{s}$ & 4800 & 0.07 & 65.5 & $\overline{\mathrm{T}}_{\mathrm{s}}$ & 0.998482 \\
\hline INTERFLOW & DOWNSTREAM & | 482 & $Q_{i}$ & 14970 & 0.11 & 57.2 & $\overline{\mathrm{T}}_{\mathrm{i}}$ & 0.999244 \\
\hline LOWINTERFLOW & UPSTREAM & 285 & $Q_{u}$ & 3800 & 0.075 & 51.6 & $\overline{\mathrm{T}}_{\mathrm{u}}$ & 0.999615 \\
\hline UNDERFLOW & UPSTREAM & 32 & $Q_{u}$ & 900 & 0.035 & 48.6 & $\overline{\mathrm{T}}_{\mathrm{u}}$ & 0.999766 \\
\hline TUNNEL CREEK & DOWNSTREAM & 625 & $Q_{c}$ & & & 54.8 & $\bar{T}_{c}$ & 0.999421 \\
\hline
\end{tabular}

Table 4--Data on entrance mixing and interflow temperature, section CC, June 18, 1944

\begin{tabular}{|c|c|c|c|c|}
\hline \multicolumn{3}{|c|}{ ENTRANCE MIXING } & \multicolumn{2}{|l|}{ INTERFLOW MEAN TEMP. } \\
\hline \multirow[t]{2}{*}{ HOW OBTAINED } & $\begin{array}{l}\text { MIXING RATE } \\
Q_{m} \text { (cfs) }\end{array}$ & $\begin{array}{l}\text { MIXING RATIO } \\
Q_{m} / Q_{c}\end{array}$ & HOW OBTAINED & \multirow[t]{2}{*}{$\overline{\mathrm{T}}\left({ }^{\circ} \mathrm{F}\right)$} \\
\hline & \multicolumn{3}{|c|}{ USING DATA FROM TABLE 3} & \\
\hline \multirow{3}{*}{$\begin{array}{l}\text { EQ.(1a) } Q_{s}+Q_{u}=Q_{m} \\
\text { EQ.(2a) } Q_{i}-Q_{c}=Q_{m}\end{array}$} & 653 & \multirow[t]{2}{*}{1.02} & $E Q$ (3a) $\frac{Q_{S} T_{S}+Q_{u} T_{u}+Q_{c} T_{C}}{Q_{s}+Q_{u}+Q_{c}}=T_{i}$ & 56.79 \\
\hline & 857 & & GRAPHICAL INTEGRATION & 57.20 \\
\hline & \multicolumn{3}{|c|}{ USING ADJUSTED VALUES OF $Q_{S} \& Q_{U}$} & \\
\hline \multirow{3}{*}{$\begin{array}{c}Q_{m} \text { ASSUMED: } \\
\text { SEE TEXT } \\
\text { EQ.(Ia) AFTER SOLV- } \\
\text { ING EQ.(3a) FOR Q } \\
\text { DITTO }\end{array}$} & 857 & 1.37 & EQ. (3a) & 56.90 \\
\hline & 609 & 0.98 & ASSUMED & 56.84 \\
\hline & 722 & 1.16 & ASSUMED & 57.20 \\
\hline
\end{tabular}

As calculated from interflow data $Q_{i}$ was $1482 \mathrm{cfs}$, which is $204 \mathrm{cfs}$ greater than the total flow into the mixing zone as shown in Table 3. Prorating this additional flow to the three upstream currents increases $Q_{\mathrm{S}}$ to $440 \mathrm{cfs}$, the low interflow to $375 \mathrm{cfs}$, and the underflow to $42 \mathrm{cfs}$. A homogeneous mixture of these flows with that of Tunnel Creek would have a temperature of $560^{\circ} 8 \mathrm{~F}$. This agrees fairly well with the $57: 2$ figure obtained by graphical integration of velocity and temperature measurements made within the interflow.

$\mathrm{Q}_{\mathrm{S}}$ was found to be $292 \mathrm{cfs}$ by (3a) when $\overline{\mathrm{T}}_{\mathrm{i}}$ was assumed to be $56: 84 \mathrm{~F}$, the average of the values obtained for $\bar{T}_{1}$ by (3a), and all other values were taken from Table 3 . This is to be compared with $336 \mathrm{cfs}$ from field measurements and $440 \mathrm{cfs}$ by proration as described in the preceding paragraph. These are reasonable variations in view of the exceptionally complex flow pattern prevailing in the 
upper 15 feet of the cross section. The surface current decreased in velocity with depth and across the section from north to south. It varied in thickness from less than two feet to more than four feet. Beneath it there was a layer some ten to 13 feet thick in which velocities varied from 0.0 to $0.1 \mathrm{fps}$ and the flow was literally in all directions, being upstream, downstream and more or less parallel to the cross section, depending upon depth and station.

The complexity of the flow at all stations and all depths is indicated by the velocity profiles in Figure 4. It should be noted that at three of the stations the downstream flow increased in velocity with depth, then fell off only to increase again almost to the previous maxima before returning to zero. At the two stations where the water was more than $\mathbf{5 5}$ feet deep there were two fairly pronounced maxima in the current or currents flowing upstream beneath the interflow. A study of the profiles for these two stations shows that at one there were apparently five and at the other there were possibly seven fairly distinct currents rather than the usual three.

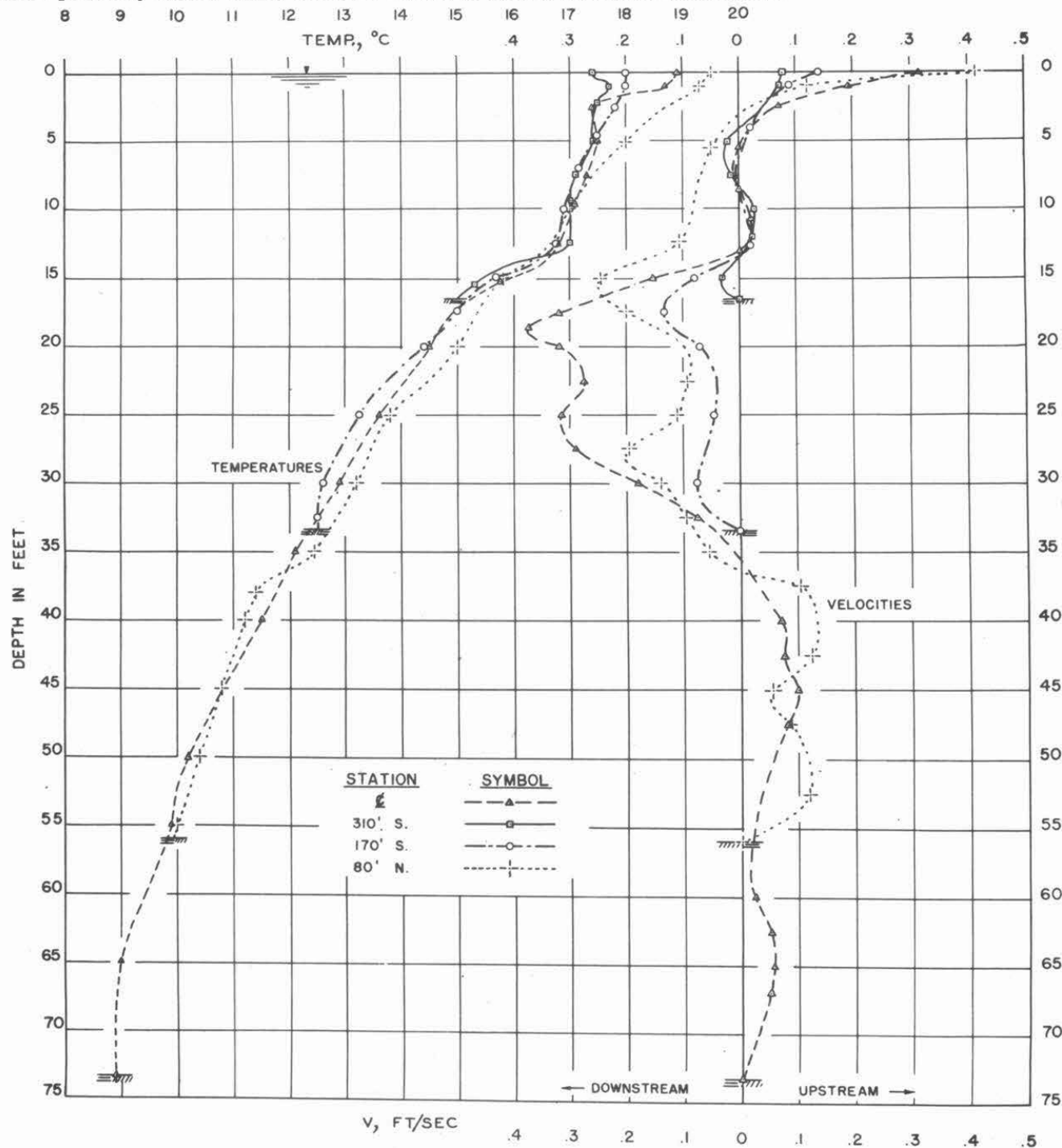

Fig. 4--Temperature and velocity profiles for four stations on cross section CC, June 28,1944 
Table 4 shows that the interflow was from 98 ṕer cent to 137 per cent greater than Tunnel Creek, as compared with 75 per cent to 96 per cent on June 6 and 7, 1944. On June 28 the difference in specific gravity between the water of Tunnel Creek and that of the two reservoir currents with which it mixed were 0.009 and 0.002 as compared with 0.008 and 0.001 previously. If (2a) is used to find the magnitude of entrance mixing on each occasion, the figure is $851 \mathrm{cfs}$ for the first, and $857 \mathrm{cfs}$ for the other even though the discharge of Tunnel Creek had decreased to only 55 per cent of its former vlaue. Why small flows may mix more efficiently than large ones will be discussed after the presentation of other data.

June 1,3 , and 16, 1944--On June 1,3 , and 16, data were taken at the center of cross section CC but not elsewhere. Although these data alone are inadequate for calculating the mixing demand on those days, a procedure has been developed that permits estimates to be based upon them. For those days on which fairly complete data were obtained, the flows through the cross section were recalculated as if the values measured at each elevation on the central vertical were valid for the entire section at that elevation. When these new values were compared with those obtained by the use of data from all stations it was possible to determine approximately what corrections were necessary. This procedure leaves much to be desired but the results, as tabulated in Table 5 , compare favorably with those obtained from more complete data, and already presented. On June 1 and 3, 1944 when the discharge from Tunnel Creek was of the order of $1000 \mathrm{cfs}$, the mixing ratios (Table 5, columns 8 and 9) varied from 0.68 to 0.76 . Measured and calculated values of $\overline{\mathrm{T}}_{\mathrm{i}}$ (columns 11 and 12 ) show remarkably close agreement on June 3 and 16 , and a discrepancy of less than one degree on June 1 .

On June 16, the discharge had fallen to $635 \mathrm{cfs}$ and the mixing ratio values were 1.46 and 1.68 , as compared with 0.98 and 1.37 for a discharge of $625 \mathrm{cfs}$ on the 28 . The mean temperatures on June 16, as shown in Table 5, columns 11 and 12, are nearly identical and could be interpreted as indicating that 1.68 is closer to the true value than is 1.46 , which, in turn, does not differ greatly from the 1.37 of June 28. Incidentally, the mean of the four mixing ratios cited in this paragraph is 1.37 .

Table 5 --Summary of results from data for central station of cross section CC

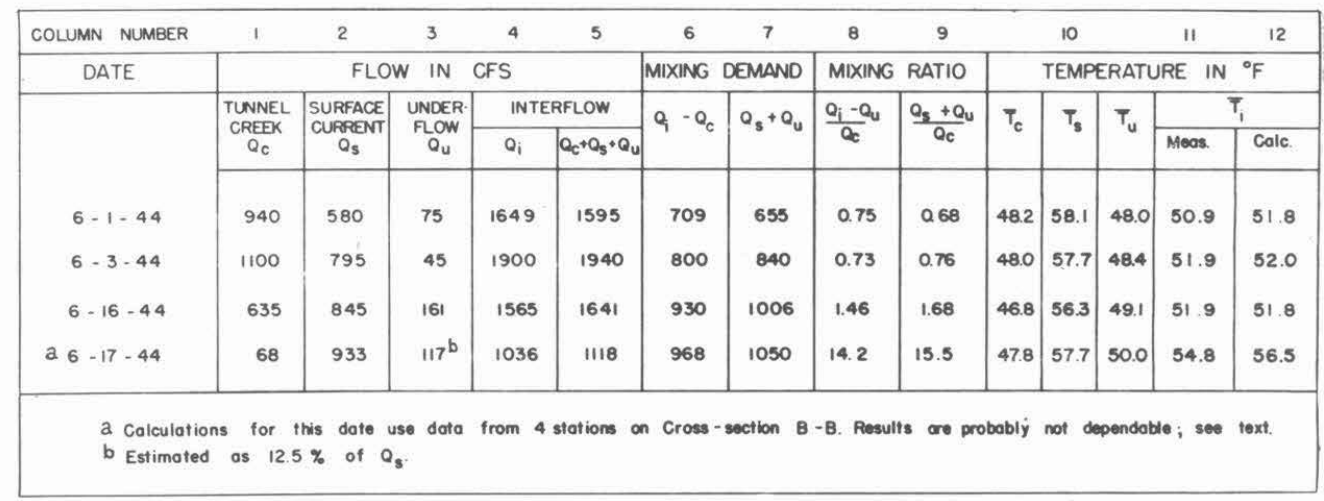

Mixing ratios for small discharges--It has been assumed, thus far, that all upstream flow into the mixing area was consumed in the process of entrance mixing. Actually, this is never true because some water is always dragged downstream by the interflow because of interfacial friction. It thus becomes a part of the interflow without having participated in entrance mixing. Nevertheless it is dragged out of the mixing area and a certain portion of the upstream flow is needed to replace it. The quantity at Shaver Lake was not thought to be great enough to demand consideration in the present calculations.

When the discharge from Tunnel Creek was greater than $500 \mathrm{cfs}$, the assumption that all upstream flow was the result of entrance mixing was probably essentially valid, but for small flows it very definitely was not. Just as the interflow drags water along by interfacial friction, so also a breeze drags the surface layer of the reservoir. At Shaver Lake this breeze was upstream throughout the hours when data were being taken. When discharges from Tunnel Creek were small the quantity of water dragged upstream by the wind may have greatly exceeded the mixing demand. 
On June 17, 1944, the flow. in Tunnel Creek had dropped to $68 \mathrm{cfs}$ from 635 cfs on the previous day. The interflow moved through cross section $\mathrm{CC}$ at velocities too low to actuate the current meter. Consequently, data were taken at four stations on cross section B-B, located about 650 feet from the mouth of Tunnel Creek. Even at this comparatively favorable location no velocity data were obtainable in the area below the interflow. When the usual treatment was applied to the data from cross section BB the indicated mixing ratios were 14.2 and 15.5 . Table 5 , columns 6 and 7, shows that the mixing demand was as great as might have been expected for discharges in excess of $1000 \mathrm{cfs}$. There was unusually close agreement between measured and calculated values of $Q_{i}$, as shown by columns 4 and 5 , but the difference between $\bar{T}_{i}$ by integration and by (3a), as shown in columns 11 and 12, was about twice as great as that shown by any other set of data presented here. Interflows of the size indicated could not have escaped detection at cross section CC, but repeated attempts at that location falled to show velocities high enough to run the current meter. There are, therefore, several reasons for doubting the validity of mixing ratios as high as 14 or 15 for June 17.

For several weeks the discharge of Tunnel Creek had been greater than 600 cfs. During that time two great eddies developed and persisted in the mixing zone, rotating in opposite directions about vertical axes like a pair of meshed gears. Several hundred acre feet of water were involved in this circulation pattern. During the afternoon of June 16 the discharge of Tunnel Creek decreased rapidly from $635 \mathrm{cfs}$ to about $70 \mathrm{cfs}$. It seems entirely possible that the established circulation pattern continued during the period when data were being taken on the following day. If so, it could result in the movement of considerable quantities of water upstream through cross section BB, which was located in the upstream half of the eddy area. The fact that eddy circulation of this kind was not observed and does not seem to be indicated by the data could be a result of the selection of measuring stations at locations where only the upstream flow of these eddies was encountered, with the corresponding downstream flow occurring between stations. Under these circumstances the indicated mixing ratio could be very much greater than the actual one.

Re-examination of the data shows that there were no interfaces of the usual kind at which are found sharp breaks in the temperature gradient and a sudden reversal in the direction of flow. However, at depths of from 12.5 feet to 20 feet, depending upon the vertical at which measurements were made, there was an area of nearly motionless water above which there was no downstream flow and below which there was no upstream flow of sufficient strength to register on the current meter. This dividing line coincided conspicuously with the $56^{\circ} \mathrm{F}$ temperature contour.

The steepest part of the temperature gradient was found several feet below the $56^{\circ} \mathrm{F}$ contour. Immediately above and below this break measurable velocities were found in what may have been two distinct downstream currents. Perhaps the upper one contained the excess from the surface flow that had been blown into the area and, possibly, the lower one was a true density current produced by entrance mixing. The lztter current was bounded by the $52^{\circ}: 5$ and the $500^{\circ} 5$ contours, had a mean temperature of $51.8 \mathrm{~F}$ and a flow of $385 \mathrm{cfs}$. If it is assumed that it contained all the flow from Tunnel Creek, mixed with $317 \mathrm{cfs}$ of stored water, the mixing ratio was 4.67 . $\overline{\mathrm{T}}_{\mathrm{S}}$ was $57^{\circ}: 8$, $\overline{\mathrm{T}}_{\mathrm{u}}$ was $50^{\circ} 0$ and $\overline{\mathrm{T}}_{\mathrm{c}}$ was $47^{\circ}: 8$. If the $68 \mathrm{cfs}$ from Tunnel Creek were mixed with $106 \mathrm{cfs}$ from the surface current and $211 \mathrm{cfs}$ from the underflow, the resulting interflow would have a volume of $385 \mathrm{cfs}$ and a mean temperature of $51{ }^{\circ} 8$. This combination fits the field data for the interflow exactly. The temperature of Tunnel Creek was such that mixing with water from the lower levels would be easier than with water from the surface because of the smaller difference in specific gravity. Between the surface current and Tunnel Creek the difference in specific gravity was 0.00061 , but when the mixture of these two reached the lower mass of water the difference was less than one-third as great, 0.00019. This makes the admixing of an unusually high percentage of water from the lower levels, as suggested above, seem likely.

Factors governing the mixing ratio--There is a consistent trend in the Shaver Lake data indicating that the mixing ratio is influenced principally by three variables: (1) Difference in specific gravity; (2) the available specific energy; and (3) the hydraulic radius. This is not the conventional hydraulic radius obtained by dividing the cross-sectional area by the wetted perimeter but a special one in which the cross-sectional area is divided by that portion of the perimeter which is in contact with other fluid masses. It is only the interfacial portions of the perimeter that are considered. For underflows and overflows this portion is usually less than 50 per cent, but for interflows it ordinarily is greater and often is the entire perimeter.

In general, any increase in the difference in specific gravity or in the hydraulic radius tends to decrease mixing whereas any increase in specific evergy tends to increase it. 
The difference in specific gravity is important primarily because it determines to what extent gravity may be effective in preventing the mixing of adjacent fluid masses. It is not too obvious that the cold water at the bottom of a lake is being buoyed up by the warmer water above it, or that the lake itself is being buoyed by the overlying atmosphere. All of us realize, however, that less energy is expended when we lift a bucket of water from the bottom of a well to the surface of the water in the well than when we lift that same mass an equal distance through the air. On the one hand gravity is almost completely offset by buoyancy, but on the other the buoyancy is so small as to be negligible. Since mixing involves moving fluid masses, it follows that, other things being equal, the more nearly alike the specific gravities of the fluids to be mixed, the more readily they will mix because the stabilizing influence of gravity is less effective.

The effective gravity, $g_{e}$, may be determined readily from the equation $g_{e}=g\left(s-s^{\prime}\right) / s$, where $\mathrm{g}$ is the normal gravitational acceleration, $\mathrm{s}$ the specific gravity of the heavier fluid, and $\mathrm{s}^{\prime}$ the specific gravity of the lighter one. At no time during the field investigations at Shaver Lake was $\mathrm{ge}_{\mathrm{e}}$ as great as $0.032 \mathrm{ft} / \mathrm{sec}^{2}$, and often it was little more than $0.003 \mathrm{ft} / \mathrm{sec}^{2}$. It should be noted that this latter figure is roughly 0.0001 of the normal value of gravity. The very fact that there were density currents is proof that gravity forces of even these small values are not entirely negligible. It seems inprobable, however, that such variations as there were in ge were important causes of the observed differences in the mixing ratio.

The statement that any increase in the available specific energy tends to increase mixing is not one that can be proved by the data from Shaver Lake. Slopes near the mouth of Tunnel Creek are so steep that the discharge is white with entrained air when it enters the lake, as Figure 5 shows clearly. The entrance velocity apparently remained nearly constant at about 12 fps regardless of the discharge, according to estimates made by using floats under unusually difficult circumstances. Velocities probably were slightly higher for the larger discharges and, if so, there must have been some increase in the available specific energy. Nevertheless, the mixing ratio decreased consistently as the discharge increased.

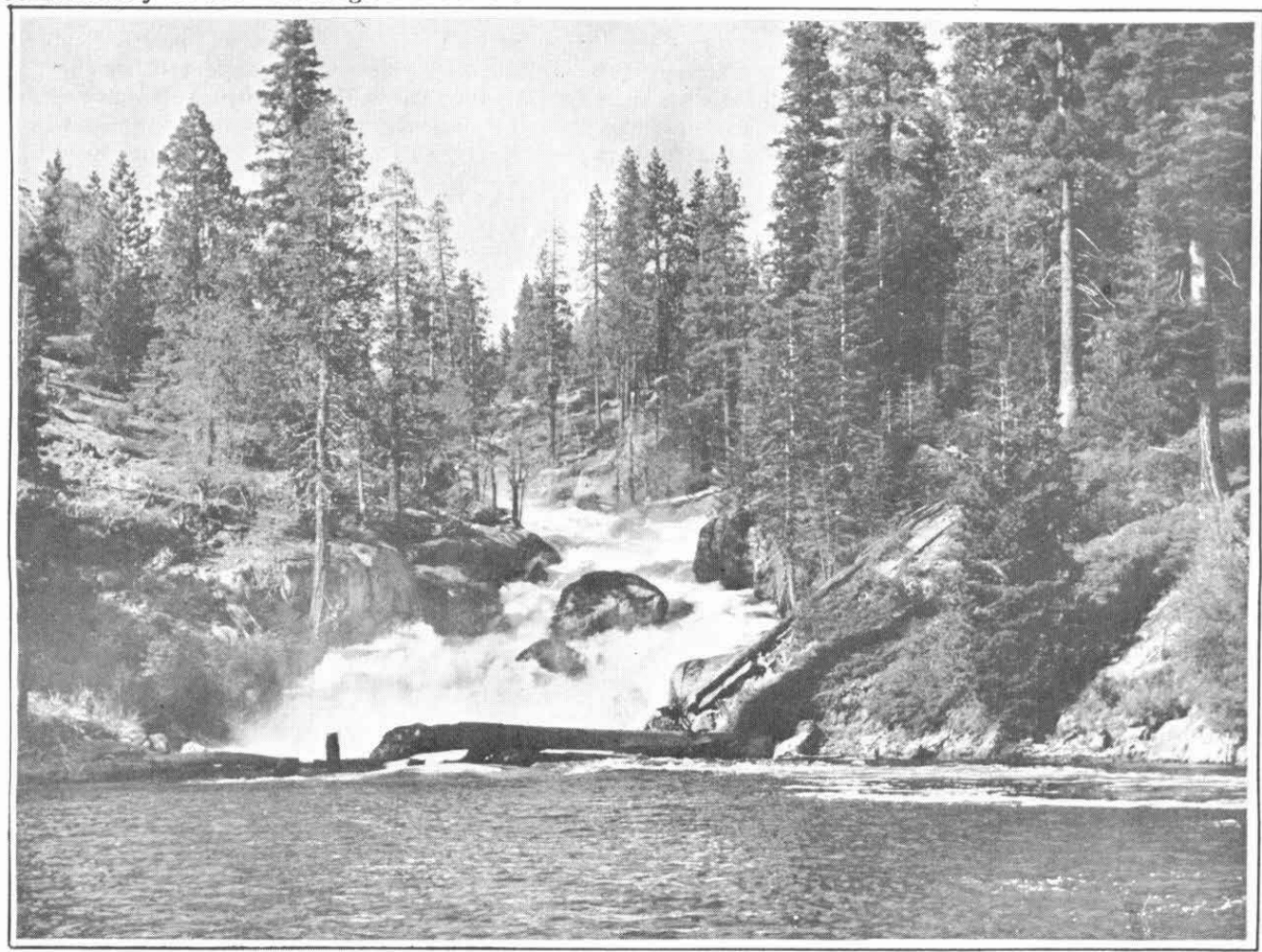

Fig. 5--Tunnel Creek as it enters Shaver Lake 
By process of elimination it must be concluded that the third factor, the hydraulic radius, accounts for the observed variations in the mixing ratio. Obviously it is impossible to mix two fluid masses, regardless of the energy available, unless they can be brought into direct contact with each other. Obviously, also, the greater the area of contact per unit volume the greater the opportunity for mixing. Fundamentally, it is a problem of specific surface. If the geometry of the flow remains constant, the area of contact per unit volume increases at an ever accelerating rate as the size decreases.

Flattening of the cross section decreases the hydraulic radius. Both interflows and overflows usually become thin because of the remoteness of channel walls. The hydraulic radius may be small, then, either because of the size or the shape of the croos section. In large, thick flows, much of the energy that could cause mixing is buried in the depths of the mass where it is dissipated in ineffective stirring, but small and thin flows are much more efficient mixers because a higher percentage of the available energy is near the boundary through which mixing must take place.

Undoubtedly, the interflows at Shaver Lake were proportionally thinner for small discharges than for large ones. With both size and shape combining to reduce the hydraulic radius, very small discharges like that of June 17, 1944, resulted in higher mixing ratios.

Summary and conclusions--Entrance mixing produced thermal density currents at Shaver Lake that were from less than twice to nearly five times the size of the inflowing streams. The hydraulic radius, the difference in specific gravity, and the available specific energy are the chief factors influencing entrance mixing. Small inflows tend to mix more readily than large ones. At Shaver Lake, entrance mixing lid not quite double the volume of flows of $1000 \mathrm{cfs}$, more than doubled those of approximately $600 \mathrm{cfs}$, and may have increased those of less than $100 \mathrm{cfs}$ by as much as fivefold. A twenty-fold range in the discharge of Tunnel Creek is believed to have produced a sevenfold range in the mixing ratio.

Differences between the specific gravity of the inflowing and the impounded water were extremely small, and inflow velocities were high in comparison with those to be expected for the Colorado River at Lake Mead and for the Rio Grande at Elephant Butte Reservoir. It seems proable, therefore, that the mixing ratio at Shaver Lake is somewhat higher than can be expected in reservoirs where turbid density currents make entrance mixing an important consideration reservoir operation.

Acknowledgments--The generous assistance and wise counsel of Robert T. Knapp, Vito A. Vanoni, and H.A. Einstein in planning the field work and interpreting the data are gratefully acknowledged. Able assistance in the field was given by James T. Rostron, Helen $\mathbf{R}$. and John S. Bell, and by Eric Bergh, Fred Swanson, and many others of the Big Creek staff of the Southern California Edison Company. The cooperation of Wm. A. Lang, also of the Edison Company, has been of great value. Rostron and James D. Savage prepared the illustrations.

\section{$\underline{\text { Reference }}$}

KNAPP, ROBERT T., Density currents: Their mixing characteristics and their effect on the turbulence structure of the associated flow, Proc。Sec. Hyd. Conf, Bull。27, Univ. of Iowa Studies in Engineering, 1943.

U. S. Department of Agriculture, Soil Conservation Service,

California Institute of Technology, Pasadena, California

(Manuscript received October 31, 1\$46; presented at the Regional Meeting, Section of Hydrology, Sacramento, California, February 27, 1946; open for formal discussion until March 1, 1948.) 